Turk. J. Math. Comput. Sci.

13(2)(2021) 403-417

(C) MatDer

DOI : $10.47000 /$ tjmcs. 905508

\title{
Modeling Covid-19 Infection Cases and Vaccine in 5 Countries Highly Vaccinations
}

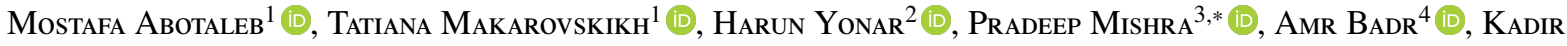 \\ KARAKAYA $^{5}$ (i) AYNUR YONAR ${ }^{5}$ (D) \\ ${ }^{1}$ Department of System Programming, South Ural State University, Chelyabinsk, Russia. \\ ${ }^{2}$ SelçukUniversity, Faculty of Veterinary Medicine,Department of Biostatistics, Konya, Turkey. \\ ${ }^{3}$ College of Agriculture,Powarkheda,J.N.K.V.V. (M.P.) India. \\ ${ }^{4}$ University of New England, Faculty of Science, School of Science and Technology, Armidale, Australia. \\ ${ }^{5}$ Selçuk University, Faculty of Science, Department of Statistics, Konya, Turkey.
}

Received: 04-04-2021 • Accepted: 10-12-2021

\begin{abstract}
Aвstract. COVID-19 has become the most important and crucial agenda in the world in the last year. COVID-19 has taken many lives around the world and millions of people have been infected. To get rid of this depression caused by COVID-19, many countries have started big campaigns for vaccine production. In this study, data on infection cases and vaccinations conducted in England, Germany, Israel, Russia, and the USA were analyzed from January 3, 2020, to March 3, 2021. We used univariate time series models, where the results are very accurate, rather than epmdicolgical models. In this article we used BATS, TBATS, Holt's linear trend, and ARIMA models to recognize the pattern of spread of covid 19 infection cases. The best models are specified for all countries that have the least error according to MAPE. Findings obtained in this study have been reported extensively in England, Germany, Israel, Russia, and the USA with tables and figures. Using the results and forecasts obtained in this study, England, Germany, Israel, Russia, and the USA can take COVID-19 measures for the future.
\end{abstract}

2010 AMS Classification: 93C70

Keywords: ARIMA, BATS, Covid-19, Holt's Linear, TBATS

\section{INTRODUCTION}

Since the COVID-19 pandemic was detected, the World has publicly announced that a successful and correct vaccine method can be used to control the outbreak. Countries that understand that vaccines are essential disease-prevention tools have been stolen with no opportunity for investigation. Although the new coronavirus disease kept doing fatal damage, on the other hand, positive news about the vaccine started to surface as the capacity of the new technology was being mobilized Vaccines carried out by many companies have been developed in two types as RNA-based or viral vector vaccines, and it has been announced that they have different degrees of efficacy. While discussions on the effectiveness of vaccines continue, countries have become competing with each other at the point of vaccination in order to avoid the pandemic. Although each country has adopted different vaccination strategies, their common point was to vaccinate society as soon as possible and gain social immunity. In this sense, countries have put emergency

*Corresponding Author

Email addresses: abotalebmostafa@bk.ru (M. Abotaleb), makarovskikh.t.a@ susu.ru (T. Makarovskikh), hyonar@ selcuk.edu.tr (H. Yonar), pradeepjnkvv@gmail.com (P. Mishra), Amr.Mostafa@live.com (A. Badr), istatistikadir@gmail.com (K. Karakaya), aynursahin@ selcuk.edu.tr (A. Yonar) 
action plans into effect in establishing financial infrastructure, creating a vaccination program, and participating in vaccines.

Previously, studies modelling the course of the epidemic found a place in the literature. Researchers made evaluations about the course of the epidemic, using predictive models of Covid-19 infection cases. They conducted studies that gave an idea to countries in their evaluations using infection cases predicting infections and death [21] estimated the number of COVID 19 outbreak cases with some curve estimation models Box-Jenkins (ARIMA) and Brown / Holt Linear exponential smoothing methods for G8 countries and also assessed the situation of the epidemic.

[20] used the selected countries which have a different pandemic strategy and modeled with compartmental (SEIR) and various statistical models (curve estimation models, ARIMA, Brown Linear Exponential Smoothing Method, ARDL) to detect the progress of the pandemic. [18] proposed a simple Multiple Linear Regression model for optimized to use phone call data to forecast the number of daily confirmed cases and offered a probabilistic forecast that allows decision-makers to better deal with risk.

The article [2] discusses an algorithm that allows obtaining a forecast using several linear models for short-term forecasting and the epidemiological SIR model. The considered algorithm is extensible, and various modules can be connected to it to provide the construction of forecasts by various methods, and concluded that the Sir model has a lot of error for forecasting Covid-19 infection cases. By Ensembling models in the time series models, errors can be reduced by using a prioritizer for models and giving weights for time series [13]. The article [3] discusses a new algorithm implemented with R, predicting COVID-19 cases and choosing the best model (BATS, TBATS, Holt's linear model, ARIMA, SIR, and NNAR) for forecasting. The developed algorithm helped to identify the pattern of infection.

In [4] "Epidemic.TA" can automatically select the appropriate model to obtain forecasts with very low MAPE because of the choice of the best model for the time-series used as input data. If we fix the current circumstances (lockdown constraints, vaccine availability and velocity of vaccination, the capacity of hospitals, etc., we can observe the development situation in mid-term or long-term forecasting.

The main results obtained include the following [12]. It is shown that the parameters of the model are different for different regions, in addition, the parameters of the model change over time. The study of the regularities of changing the parameters of the model remains an open problem. The paper considers the possibility of automatic selection of the parameters of the ARIMA model for time series corresponding to the same process occurring in different conditions (the spread of coronavirus infection in different regions of the Russian Federation). A script in the R programming language has been developed, which makes it possible to predict the total cases of infection and deaths for a selected period of time in a region or state specified by the user using the standard auto.arima library. It is shown that the automatic selection of parameters in a number of cases does not allow choosing, in fact, the best model. Investigation of cases of errors in the automatic selection of model parameters is a topic for further research. The developed script is included in the general library of epidemic.ta scripts for forecasting Covid-19 time series.

We analyzed the Covid-19 first wave impact on the PSX returns [10]. The public, industries, small businesses, and interest rate relief packages have declined. It illustrates that the pandemic affects the stock markets of developing countries more than industrialized economies. In this case, we expect improved market conditions to remain at low progress, average progress, and substantial progress. In March of 2020, China has shown a relative improvement compared to other countries in terms of recovered cases and deaths [1]. However, China remains the most affected country when compared to Italy and the U.S. The Chinese health system per 100,000 citizens has 3.6 beds in intensive care units, but with the slight increase in confirmed cases, China can expand the construction of mobile ICUs. They used the ARIMA model and the results were very accurate [15]. That's concluded. Sugarcane production in India has increased in recent years, with major states like Uttar Pradesh, Maharashtra and Karnataka increasing production. Tamil Nadu and Andhra Pradesh production of sugarcane decreased in the years 2019-25 from 2015-2020. It is expected to increase in 2025 to 40.6468 million tons in the whole of India.

[14] compared ANN, fuzzy and ARIMA models for COVID-19 projection for total cases and infection. In another study, Mishra et.al (2020) used the machine learning model and SARIMA models for COVID-19 total death and infection cases in India. [17] used SARIMA model of COVID-19 infection cases for Ghana. With the invention of the vaccine, studies in the literature left their place to models, including vaccinated individuals. Prediction of the 
progression of the epidemic became possible by examining and evaluating the immunity of the community. In this sense, studies on vaccines gained importance and began to take place in the literature. There is quite a limited number of studies in the literature since vaccination is at the beginning level. [5] made evaluations about priority vaccination with mathematical models. They also demonstrated an approved modeling approach for evaluating and comparing vaccine prioritization strategies.

[19] aimed to understand the public perceptions regarding a future COVID-19 vaccine in Australia and also demonstrated society's attitude towards vaccination. They evaluated the vaccine studies based on the clinical findings of a candidate vaccine study. These studies started to find more place in the literature day by day with the increase of vaccination and it is a fact that each of them is additive.

In this study, Russia, the United States, Germany, England, and Israel were each used as infection case data for vaccination studies. Some selection criteria were used to determine the most suitable models among BATS, TBATS, Holt's linear trend, and ARIMA models. According to the model predictions, the countries were permitted to determine and implement long-term policies. This modeling study was built around uncovering the current situation and gathering information about what the progression of the pandemic will look like in the days ahead.

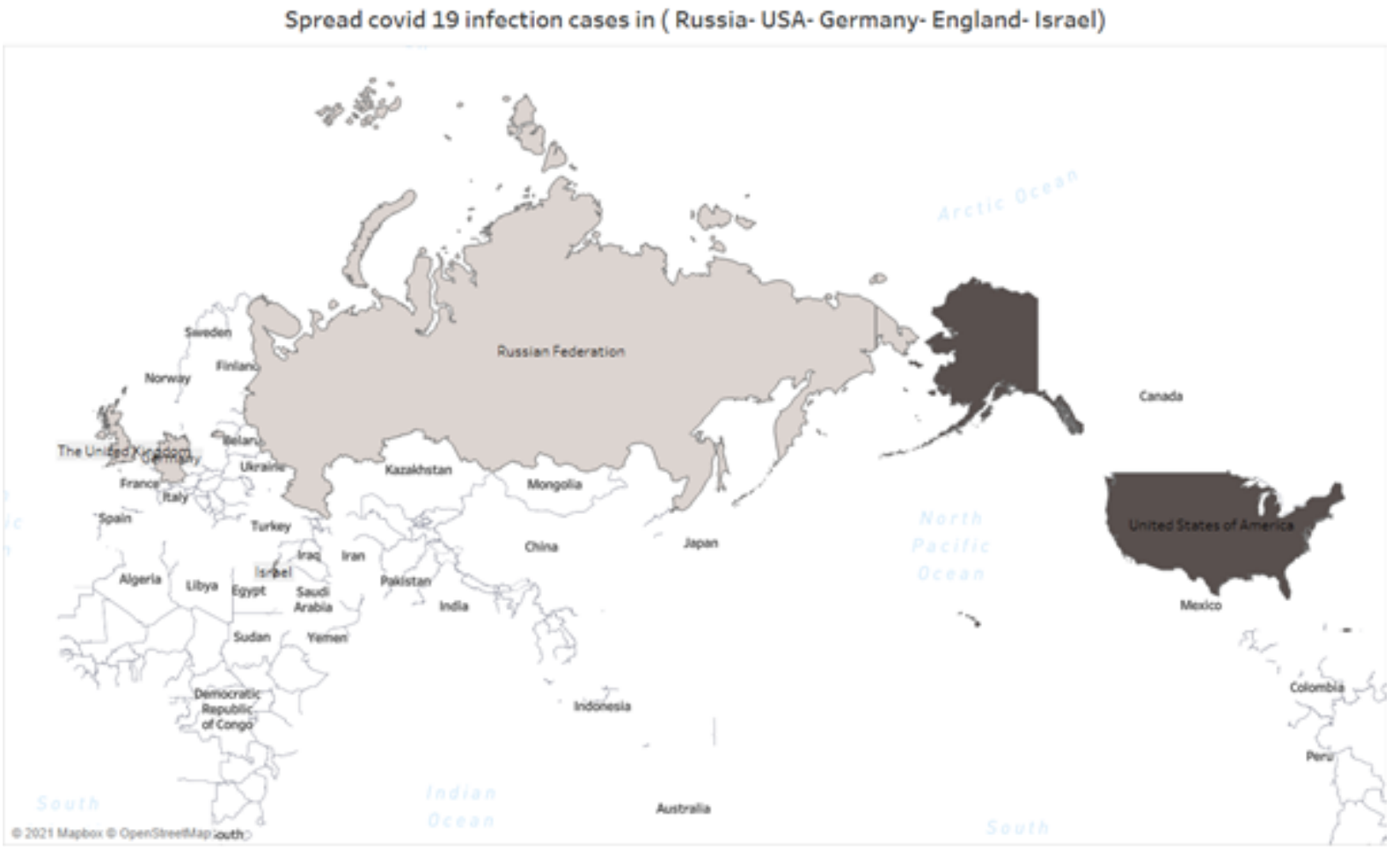

Figure A: Spread of COVID19 infection in (Russia-USA-Germany - England- Israel.

\section{Material AND Methods}

Present investigation data is collect from https://covidvax.live/ for total infection and vaccination of five countries. Statistical analysis has been done using R statistical software.

2.1. BATS and TBATS Models. TBATS is an improvement modification of BATS that allows multiple seasonal incorrect cycles from figure number B. TBATS has the following equation [7] from figure number $\mathrm{C}$ that represented BATS and TBATS model is a Box-Cox transformation, error modeled by ARMA. 


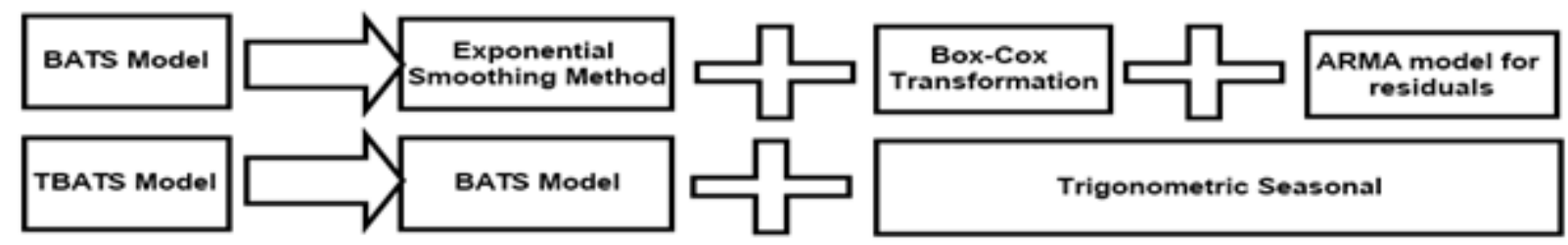

Figure B: BATS and TBATS model.

Models based on the Box-Cox transformation and ARMA model, take into account Trend and Seasonality (BATS) and its trigonometric modification.

Box-Cox transformation:

$$
y_{t}^{(w)}=\left\{\begin{array}{l}
\frac{\left(y_{t}^{\omega}-1\right)}{\omega}, \omega \neq 0 \\
\log \left(y_{t}\right), \omega=0 .
\end{array}\right.
$$

Observations:

$$
y_{t}^{(w)}=l_{t-1}+\phi b_{t-1}+\sum_{i=1}^{M} s_{t-m_{i}}^{(i)}+d_{t}
$$

where

- $b_{t}=(1-\phi) b+\phi b_{t-1}+\beta d_{t}$ reflects a global trend;

- $l_{t}=l_{t-1}+\phi b_{t-1}+\alpha d_{t}$ reflects a local trend;

- $d_{t}=\sum_{i=1}^{p} \phi_{i} d_{t-i}+\sum_{j=1}^{q} \theta_{j} \varepsilon_{t-j}+\varepsilon_{t}$ are the errors of ARMA.

Equation (2.1) has $M$ seasonal periods, each of which, in turn, consists of $s_{t}^{(i)}=\sum_{j=1}^{k_{i}} s_{j, t}^{(i)}$. Each term is modelled using a Fourier series:

$$
s_{j, t}^{(i)}=s_{j, t-1}^{(i)} \cos \lambda_{j}^{(i)}+s_{j, t-1}^{*(i)} \sin \lambda_{j}^{(i)}+\Gamma_{1}^{(i)} d_{t} ; s_{j, t}^{(i)}=-s_{j, t-1}^{(i)} \sin \lambda_{j}^{(i)}+s_{j, t-1}^{*(i)} \cos \lambda_{j}^{(i)}+\Gamma_{2}^{(i)} d_{t} .
$$

2.2. Holt's Linear Trend Method. The exponentially weighted moving average is also the averages of smoothing random variability from Figure $\mathrm{c}$ with the following advantages: (1) older data have a declining weightthat is very important that; (2) very simple to calculate; and (3) the most important for data set is that minimal data is needed. In [9], they had given three equations for forecast, level, and trend [16].

- Forecast Equation

$$
\tilde{y}_{t+h \mid t}=\ell_{t}+h b_{t},
$$

- Level Equation

$$
\ell_{t}=\alpha y_{t}+(1-\alpha)\left(\ell_{t-1}+b_{t-1}\right)
$$

- Trend Equation

$$
b_{t}=\beta\left(\ell_{t}-\ell_{t-1}\right)+(1-\beta) b_{t-1} .
$$

2.3. ARIMA Model. ARIMA model consists of three parts. The first part is (AR) that is the autoregressive, the second part is (I) integrated, and the third part is (MA). Moving Average so that model is named that Autoregressive integrated moving average (ARIMA). Sometimes data of time series not required integrated part to decline the seasonality and in that case ARIMA model represented as ARMA $(\mathrm{p}, \mathrm{q})$ model where $\mathrm{p}$ is the order of the autoregressive part and $\mathrm{q}$ is the order of the moving average and integrated part is equal zero $\operatorname{ARIMA}(\mathrm{p}, 0, \mathrm{q})$ that represented as $\operatorname{ARMA}(\mathrm{p}, \mathrm{q})$.

- AR (autoregressive term) refers to the past values used to predict the next value; defined by parameter $p$ in the autoregressive model

$$
Y_{t}=\Theta_{1} \cdot Y_{t-1}+\Theta_{2} \cdot Y_{t-2}+\ldots+\Theta_{p} \cdot Y_{t-p}+\varepsilon_{t},
$$

which is determined by PACF between $Y_{t}$ and $Y_{t-p}$, excluding the influence of $Y_{t-1}, \ldots, Y_{t-p+1}$. 


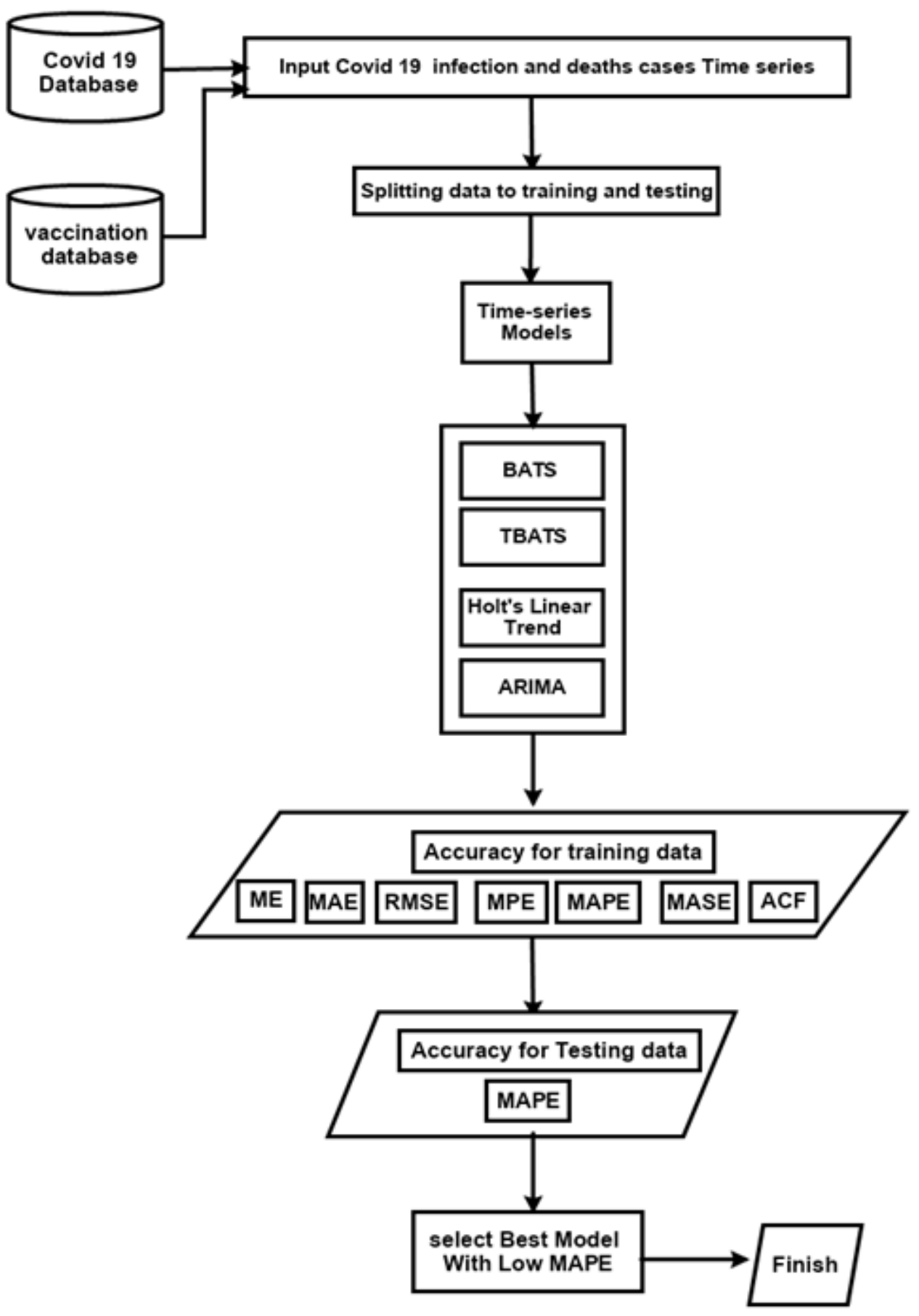

Figure c: Spread of COVID19 infection in (Russia-USA-Germany - England- Israel. 
- MA (moving average) used to determine the number of past forecast errors used to predict future values; defined by the parameter $q$ obtained from ACF

$$
\begin{gathered}
\rho_{k}=\frac{\operatorname{cov}\left\{Y_{t}, Y_{t-p}\right\}_{t}}{\operatorname{var}\left\{Y_{t}\right\}_{t}}, \\
y_{t}=\varepsilon_{t}+\alpha \cdot \varepsilon_{t-1}+\ldots+\alpha_{q} \cdot \varepsilon_{1-q},
\end{gathered}
$$

where $\varepsilon_{t}$ is white noise, which is always a stationary process. Shows the presence of fluctuations in the series.

- I (integrating term): if the series is not stationary, then its difference of order $d$ is defined, which allows getting stationary series.

After this using Ljung Box test performance of residual validated [16] and forecasting [6, 8, 11, 22].

\section{Results}

In Table 1, descriptive statistics such as mean, minimum, maximum, standard deviation, skewness and kurtosis for Covid-19 infection cases and vaccination from 3 January 2020 to 3 March 2021 are given in detail. While the average cumulative daily casesare highest in USA with 7887266, the lowest average cumulative daily cases are in Israel with 196457. Besides, while the average vaccination is highest in also USA with 31378560 , the lowest vaccinationis in Russia with 2445063. All countries have positive skewness and kurtosis both Covid-19 infection cases and vaccinations. It is concluded from the coefficient of skewness that the right tail is longer and the distribution of the Covid-19 infection cases and vaccinations for all countries. It is also concluded from the coefficient of kurtosis in Table 1 that all countries have leptokurtic distribution namely which shows fatter tails for Covid-19 infection cases and vaccinations.

TABle 1. Descriptive statistics Covid 19 infection cases

\begin{tabular}{|c|c|c|c|c|c|c|}
\hline \multicolumn{7}{|c|}{ Descriptive statistics Covid 19 infection cases } \\
\hline Country & Mean & Minimum & Maximum & Standard Deviation & Skewness & Kurtosis \\
\hline Russia & 1299057 & 0 & 4351553 & 1366731 & 0.9314486 & 2.556962 \\
\hline USA & 7887266 & 0 & 28827195 & 8958313 & 1.116434 & 2.92744 \\
\hline Germany & 615797 & 0 & 2518591 & 785874.8 & 1.313413 & 3.178923 \\
\hline England & 982447 & 0 & 4229002 & 1314063 & 1.420603 & 3.583572 \\
\hline Israel & 196457 & 0 & 806257 & 235373.4 & 1.116051 & 3.129051 \\
\hline \multicolumn{7}{|c|}{ Descriptive statistics Covid 19 Vaccination } \\
\hline Russia & 2445063 & 3357 & 6547834 & 1941351 & 0.3546031 & 1.814486 \\
\hline USA & 31378560 & 57909 & 89468175 & 27432289 & 0.5539163 & 1.997433 \\
\hline Germany & 2956418 & 18740 & 7830747 & 2286040 & 0.4735168 & 2.040614 \\
\hline England & 7591661 & 74179 & 19933433 & 6485606 & 0.4542546 & 1.755602 \\
\hline Israel & 4215574 & 7370 & 8850211 & 2856228 & 0.04865964 & 1.63237 \\
\hline
\end{tabular}

From Table 2, BATS models for Covid-19 infection cases and vaccinations in England, Germany, Israel, Russia and USA fortraining data are studied. The best-suited BATS models for Covid-19 infection cases are given respectively for the countries England, Germany, Israel, Russia and USA: BATS(1, 0,0, 1, -), BATS(1, 0,3, 1, -), BATS(1, 0,3, 1, -), $\operatorname{BATS}(1,5,2,0.984,-)$ and BATS(1, 3,5, 0.961, -). In addition, the best-suited BATS models for vaccinations are same for all countries England, Germany, Israel, Russia and USA given as BATS(1, 0,0, 1, -). Figure 1 and 2 giving the MAPE information of all testing models used in present study, In Table 3, TBATS models for Covid-19 infection cases and vaccinations in England, Germany, Israel, Russia and USA fortraining data are studied. The best-suited TBATS models for Covid-19 infection cases are the same for all countries England, Germany, Israel, Russia and USA gave as $\operatorname{TBATS}(1,\{0,0\}, 1,\{\langle 6,2\rangle\})$. 
TABLE 2. BATS Model fitted for Covid 19 infection cases and vaccination on training data $(*$ Box-Cox transformation (Lambda))

\begin{tabular}{|c|c|c|c|c|c|c|c|c|c|}
\hline \multicolumn{10}{|c|}{ BATS Model fitted for Covid 19 infection cases } \\
\hline \multirow[b]{2}{*}{ Country } & \multirow[b]{2}{*}{ Model } & \multirow[b]{2}{*}{ Lambda } & \multicolumn{2}{|c|}{ Smoothing parameter } & \multirow[b]{2}{*}{ Damping } & \multicolumn{2}{|c|}{ ARMA Coefficients } & \multicolumn{2}{|c|}{ prediction error } \\
\hline & & & Alpha & Beta & & $\mathrm{AR}$ & MA & Sigma & AIC \\
\hline Russia & $\operatorname{BATS}(1,0,0,1,-)$ & 1 & 1.036797 & 0.9146818 & 1 & - & - & 585.5735 & 8016.639 \\
\hline USA & $\operatorname{BATS}(1,0,3,1,-)$ & 1 & 0.2886957 & 0.1359761 & 1 & - & \begin{tabular}{|c|}
0.329953 \\
0.497223 \\
-0.065453
\end{tabular} & 38695.04 & 11599.26 \\
\hline Germany & $\operatorname{BATS}(1,0,3,1,-)$ & 1 & 0.1053171 & 0.1461196 & 1 & - & \begin{tabular}{|l|}
1.659754 \\
1.372889 \\
0.510494 \\
\end{tabular} & 1944.791 & 9051.31 \\
\hline England & BATS $(1,5,2,0.984,-)$ & 1 & 0.3539349 & 0.1366612 & 0.984198 & $\begin{array}{c}0.0 .533598 \\
0.725755 \\
-0.702102 \\
0.073871 \\
0.226344\end{array}$ & \begin{tabular}{|c|}
0.732587 \\
-0.207675 \\
\end{tabular} & 2314.496 & 9217.59 \\
\hline Israel & BATS $(1,3,5,0.961,-)$ & 1 & 0.01834757 & 0.141327 & 0.961198 & $\begin{array}{c}0.635632 \\
0.47436 \\
-0.288871 \\
-0.288871 \\
-0.288871 \\
\end{array}$ & $\begin{array}{c}0.703972 \\
-0.463383 \\
-0.646363 \\
0.031853 \\
0.447059 \\
\end{array}$ & 867.4313 & 8385.428 \\
\hline \multicolumn{10}{|c|}{ BATS Model fitted for Covid 19 Vaccination } \\
\hline Russia & $\operatorname{BATS}(1,0,0,1,-)$ & 1 & 0.8987151 & 0.56731 & 1 & - & - & 21171.89 & 1903.65 \\
\hline USA & $\operatorname{BATS}(1,0,0,1,-)$ & 1 & 0.7312111 & 1.702467 & 1 & - & - & 41244.62 & 1872.786 \\
\hline Germany & $\operatorname{BATS}(1,0,0,1,-)$ & 1 & 0.4959873 & 1.52628 & 1 & - & - & 3549.069 & 1363.543 \\
\hline England & $\operatorname{BATS}(1,0,0,1,-)$ & 1 & 0.9112004 & 0.8168303 & 1 & - & - & 24345.35 & 1976.578 \\
\hline Israel & $\operatorname{BATS}(1,0,0,1,-)$ & 1 & 0.8683971 & 0.5992622 & 1 & - & - & 28808.48 & 1848.228 \\
\hline
\end{tabular}

MAPE for infection cases on testieg data last 7 days from (4 march 2021) To (10 march 2021)

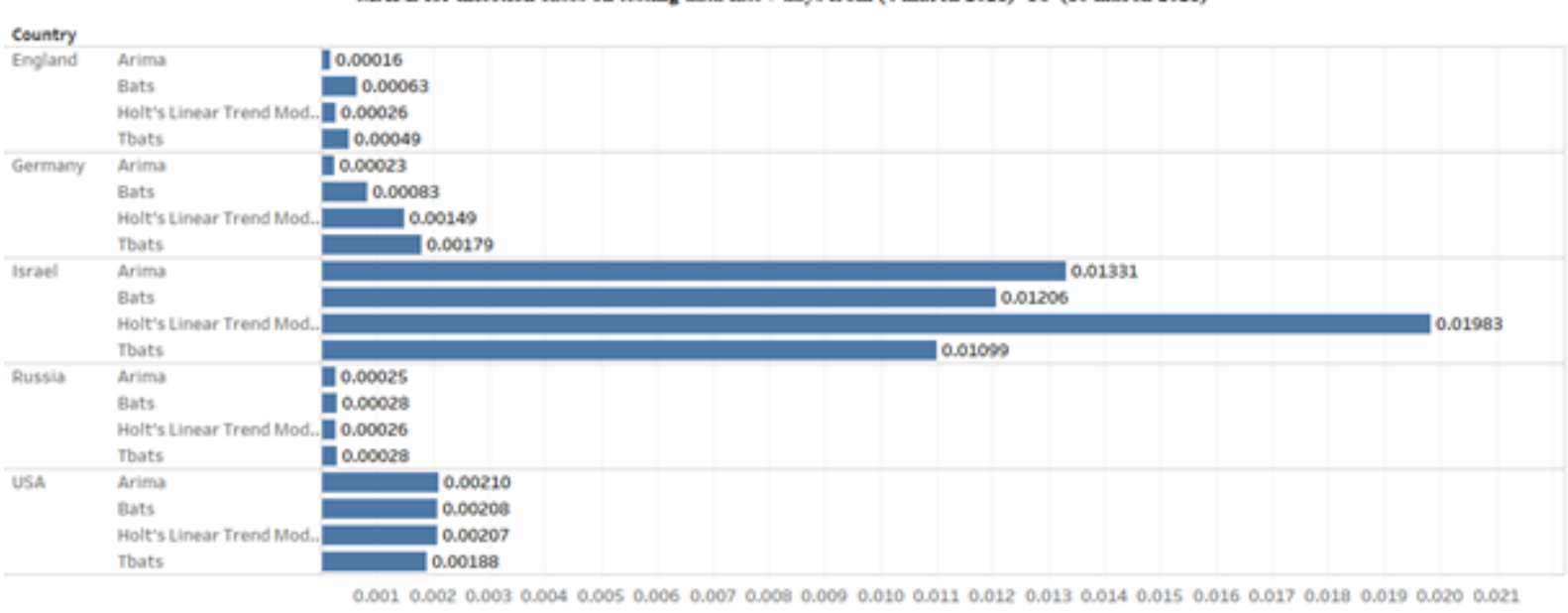

Mape

FIGURE 1. MAPE for infection cases in the five countries using testing models 


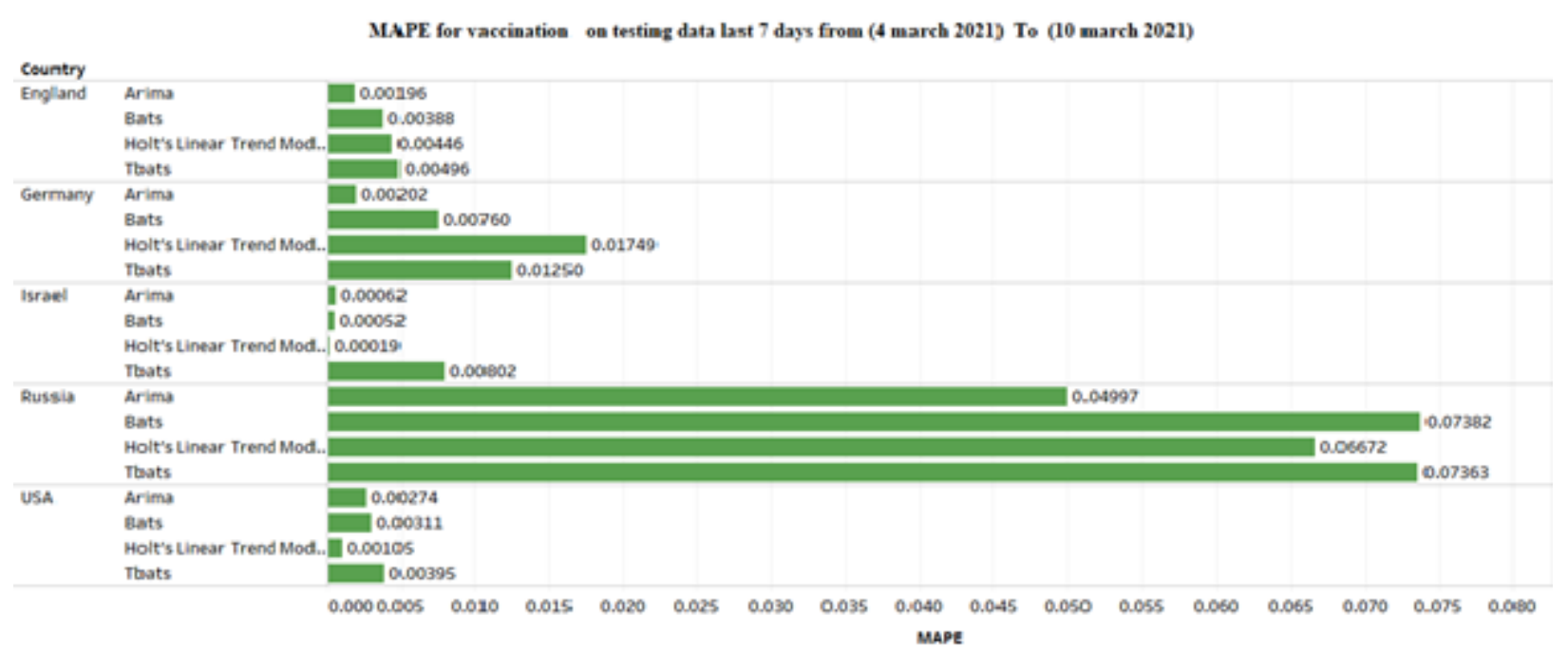

FIGURE 2. MAPE for vaccination in the top five countries using testing models

TABLE 3. TBATS Model fitted for Covid 19 infection cases and vaccination on training data(*Box-

Cox transformation (Lambda))

\begin{tabular}{|c|c|c|c|c|c|c|c|c|c|}
\hline \multicolumn{10}{|c|}{ TBATS Model fitted for Covid 19 infection cases } \\
\hline & & & \multicolumn{4}{|c|}{ Smoothing parameter } & & \multicolumn{2}{|c|}{ prediction error } \\
\hline Country & Model & Lambda & Alpha & Beta & Gamma 1 & Gamma 2 & Damping & Sigma & AIC \\
\hline Russia & TBATS $(1,\{0,0\}, 1,\{\langle 6,2\rangle\})$ & 1 & 1.039752 & 0.9126205 & -0.0002158686 & 0.001087803 & 1 & 585.1581 & 8028.035 \\
\hline USA & $\operatorname{TBATS}(1,\{0,0\}, 1,\{\langle 6,2\rangle\})$ & 1 & 0.5760051 & 0.1729011 & -0.002056009 & 0.0043265 & 1 & 41474.13 & 11658.36 \\
\hline Germany & TBATS $(1,\{0,0\}, 1,\{\langle 6,2\rangle\})$ & 1 & 1.562742 & 0.3307259 & -0.00394537 & 0.003342096 & 1 & 2275.294 & 9185.036 \\
\hline England & TBATS & 1 & 1.08207 & 0.7348984 & -0.004316243 & -0.0007762335 & 1 & 2457.049 & $\overline{9250.514}$ \\
\hline Israel & TBATS & 1 & 1.304829 & 0.3021276 & $8.404167 \mathrm{e}-05$ & -0.000 & 1 & 1000.514 & 8485.037 \\
\hline \multicolumn{10}{|c|}{ TBATS Model fitted for Covid 19 Vaccination } \\
\hline Russia & $\operatorname{TBATS}(1,\{0,0\}, 1,\{\langle 6,2\rangle\})$ & 1 & 1.005917 & 0.2916343 & $9.880239 \mathrm{e}-05$ & -0.0008792343 & 1 & 35507.13 & 1994.312 \\
\hline USA & TBATS $(1,\{0,0\}, 1,\{\langle 6,2\rangle\})$ & 1 & 0.7104187 & 1.633681 & 0.009741501 & -0.02172823 & 1 & 54167.68 & 1924.58 \\
\hline Germany & $\operatorname{TBATS}(1,\{0,0\}, 1,\{\langle 6,2\rangle\})$ & 1 & 0.8937153 & 1.158215 & 0.04214583 & -0.02112103 & 1 & 4653.615 & 1411.31 \\
\hline England & $\operatorname{TBATS}(1,\{0,0\}, 1,\{\langle 6,2\rangle\})$ & 1 & 0.9017306 & 0.7336273 & 0.002167977 & -0.001746456 & 1 & 25234.83 & 1992.319 \\
\hline Israel & $\operatorname{TBATS}(1,\{0,0\}, 1,\{\langle 6,2\rangle\})$ & 1 & 1.094104 & 0.176932 & -0.002229166 & 0.00354037 & 1 & 53288.51 & 1949.255 \\
\hline
\end{tabular}

In addition, the best-suited TBATS models for vaccinations are same for all countries England, Germany, Israel, Russia and USA given as TBATS $(1,0,0,1,\{\langle 6,2\rangle\})$.

In Table 4, Holt's trend models are investigated for Covid-19 infection cases and vaccinations in England, Germany, Israel, Russia and USA. The Box-Cox transformations for Covid-19 infection cases are given respectively for countries England, Germany, Israel, Russia and USA: 0.5949, 0.4771, 0.5663, 0.3874 and 0.4086. Also, the BoxCox transformations for vaccinations are given respectively for countries England, Germany, Israel, Russia and USA: $0.7075,0.5105,0.6510,5838$ and 0.7759 . 
TABLE 4. Holt's Linear Trend Model fitted for Covid 19 infection cases and vaccination on training data (*Box-Cox transformation (Lambda))

\begin{tabular}{|c|c|c|c|c|c|c|c|}
\hline \multicolumn{8}{|c|}{ Holt's Linear Trend Model fitted for Covid 19 infection cases } \\
\hline & & Smoothing parameter & \multicolumn{2}{c|}{ Initial states } & \multicolumn{2}{c|}{ prediction error } \\
\hline Country & Lambda & Alpha & Beta & L & B & Sigma & AIC \\
\hline Russia & 0.5949 & 0.9578 & 0.6501 & -1.8272 & -0.6536 & 3.8248 & 3728.139 \\
\hline USA & 0.4771 & 0.5844 & 0.2015 & -2.3234 & 0.0447 & 9.5948 & 4511.732 \\
\hline Germany & 0.5663 & 0.9999 & 0.996 & -2.8533 & 0.1622 & 8.0009 & 4356.949 \\
\hline England & 0.3874 & 0.9999 & 0.7404 & -2.3144 & -0.5316 & 0.5849 & 2128.281 \\
\hline Israel & 0.4086 & 0.9999 & 0.6802 & -2.6606 & -0.2734 & 0.6322 & 2194.511 \\
\hline \multicolumn{8}{|c|}{ Holt's Linear Trend Model fitted for Covid 19 Vaccination } \\
\hline Russia & 0.7075 & 0.9935 & 0.9935 & -340.2531 & 632.5928 & 132.3629 & 1107.863 \\
\hline USA & 0.5105 & 0.9999 & 0.9999 & 97.4795 & 430.3109 & 16.5298 & 728.6440 \\
\hline Germany & 0.651 & 0.9999 & 0.213 & 686.8158 & 585.7033 & 76.6251 & 855.1289 \\
\hline England & 0.5838 & 0.9999 & 0.9999 & 542.8926 & 793.8615 & 30.249 & 901.9726 \\
\hline Israel & 0.7759 & 0.9923 & 0.9923 & -3349.97 & 3449.8803 & 489.746 & 1241.084 \\
\hline
\end{tabular}

In Table 5, the ARIMA models are examined in detail for Covid-19 infection cases and vaccinations in England, Germany, Israel, Russia and USA. The best-fitted ARIMA models for Covid-19 infection cases are given respectively for countries England, Germany, Israel, Russia and USA: ARIMA(1,2,4), ARIMA(0,2,4), ARIMA(5,2,0), ARIMA(3,2,2) and ARIMA $(0,2,4)$. Also the best-fitted ARIMA models for vaccinations are given respectively for countries England,

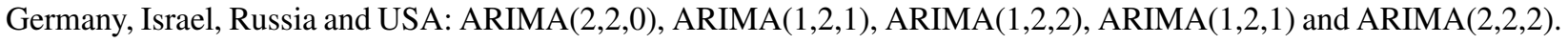
The forecasted figure of infection and total deaths cases presented in Figures 3 to 16 for the SAARC counties and China.

TABLE 5. ARIMA fitted for Covid 19 infection cases and vaccination on training data

\begin{tabular}{|c|c|c|c|c|c|c|c|c|c|c|c|}
\hline \multicolumn{10}{|c|}{ ARIMA Model fitted for Covid 19 infection cases } \\
\hline Country & Model & AR (1) & AR (2) & AR (3) & AR (4) & AR (5) & MA (1) & MA (2) & MA (3) & MA (4) & MA (5) \\
\hline Russia & ARIMA(1,2,4) & 0.7091 & - & - & - & - & -0.8876 & -0.0464 & 0.0945 & 0.2597 & - \\
\hline USA & ARIMA(0,2,4) & - & - & - & - & - & -1.2182 & 0.6514 & -0.5755 & 0.3934 & - \\
\hline Germany & ARIMA(5,2,0) & -0.1311 & -0.4253 & -0.4439 & -0.3898 & -0.5062 & - & - & - & - & - \\
\hline England & ARIMA(3,2,2) & 1.0807 & -0.6514 & -0.1829 & - & - & -1.3424 & 0.8533 & - & - & - \\
\hline Israel & ARIMA(0,2,4) & - & - & - & - & - & -0.6163 & -0.4174 & -0.2376 & 0.7089 & - \\
\hline \multicolumn{10}{|c|}{ ARIMA Model fitted for Covid 19 Vaccination } \\
\hline Russia & ARIMA(2,2,0) & 0.4923 & 0.2755 & - & - & - & - & - & - & - & - \\
\hline USA & ARIMA(1,2,1) & 0.8657 & - & - & - & - & -0.3827 & - & - & - & - \\
\hline Germany & ARIMA(1,2,2) & 0.9879 & - & - & - & - & -0.3978 & -0.3535 & - & - & - \\
\hline England & ARIMA(1,2,1) & 0.5943 & - & - & - & - & 0.3038 & - & - & - & - \\
\hline Israel & ARIMA(2,2,2) & -0.1698 & 0.5877 & - & - & - & 1.5801 & 0.7539 & - & - & - \\
\hline
\end{tabular}

The comparison of BATS, TBATS, Holt's linear trend, and ARIMA models are given in Table 6. The lowest values of the RMSE, MAE, and MAPE are shown as the best model. In Table 7, MAPEs for BATS, TBATS, Holt's linear trend, and ARIMA models are calculated for Covid-19 infection cases and vaccinations in England, Germany, Israel, Russia and USA. According to Table 7, the best-fitted models are selected the lowest values of MAPEs and reported for Covid-19 infection cases respectively for countries England, Germany, Israel, Russia and USA as ARIMA(1,2,4), TBATS Model, ARIMA $(5,2,0)$ ARIMA $(3,2,2)$ and TBATS Model. Also, the best-fitted models are selected lowest values of MAPEs and reported respectively for vaccinations for countries England, Germany, Israel, Russia and USA as $\operatorname{ARIMA}(2,2,0)$, Holt's Linear Trend, ARIMA(1,2,2), ARIMA(1,2,1) and Holt's Linear Trend. 
TABLE 6. BATS, TBATS, Holt's Linear Trend, and ARIMA Models fitted $\mathrm{f}$ on training data

\begin{tabular}{|c|c|c|c|c|c|c|c|}
\hline \multicolumn{8}{|c|}{ Covid 19 Infection cases in Russia } \\
\hline Model & ME & RMSE & MAE & MPE & MAPE & MASE & ACF1 \\
\hline BATS & 27.1769 & 585.5735 & 353.8886 & - & - & 0.03515108 & -0.001971089 \\
\hline TBATS & 27.17659 & \begin{tabular}{|l|}
585.1581 \\
\end{tabular} & 366.9142 & - & - & 0.03644488 & -0.001722792 \\
\hline Holt's linear Trend & -48.65473 & 616.3533 & 382.6579 & - & - & 0.03800867 & 0.2988623 \\
\hline ARIMA $(1,2,4)$ & 16.92737 & 551.4008 & 334.1337 & 0.3270998 & 2.400672 & 0.03318886 & 0.0109581 \\
\hline \multicolumn{8}{|c|}{ Covid 19 Vaccination in Russia } \\
\hline BATS & 1597.49 & 21171.89 & 9377.765 & 33.80856 & 78.79102 & 0.1401074 & 0.007162475 \\
\hline TBATS & 2745.354 & 35507.13 & 17579.2 & 67.86998 & 132.8823 & 0.26264 & 0.002818604 \\
\hline Holt's linear Trend & -173.4339 & 5867.358 & 3984.079 & -0.3641257 & 3.142256 & 0.05952367 & 0.5397424 \\
\hline $\operatorname{ARIMA}(2,2,0)$ & 454.076 & 4456.393 & 2056.393 & 0.4969017 & 0.6628931 & 0.0307233 & 0.0155742 \\
\hline \multicolumn{8}{|c|}{ Covid 19 Infection cases in USA } \\
\hline BATS & 491.8016 & 38695.04 & 19190.54 & - & - & 0.28825 & 0.002380726 \\
\hline TBATS & 735.0485 & 41474.13 & 20968.12 & - & - & 0.3149501 & -0.01913868 \\
\hline Holt's linear Trend & -1725.48 & 42200.71 & 19957 & - & - & 0.2997626 & -0.04963244 \\
\hline ARIMA $(0,2,4)$ & 466.0591 & 38739.61 & 19010.31 & 1.256752 & 3.02256 & 0.2855429 & -0.02207909 \\
\hline \multicolumn{8}{|c|}{ Covid 19 Vaccination in USA } \\
\hline BATS & 15268.42 & 41244.62 & 32365.16 & -1.030527 & 2.997025 & 0.03128715 & -0.07967749 \\
\hline TBATS & 15916.73 & 54167.68 & 42339.62 & -1.560978 & 5.488073 & 0.04092938 & -0.1216088 \\
\hline Holt's linear Trend & -619.385 & 40960.81 & 32149.09 & -0.3026943 & 0.4993694 & 0.03107827 & 0.4795742 \\
\hline $\operatorname{ARIMA}(1,2,1)$ & 6859.965 & 35250.86 & 26930.37 & 0.1640605 & 0.3719248 & 0.02603338 & -0.0453372 \\
\hline \multicolumn{8}{|c|}{ Covid 19 Infection cases in Germany } \\
\hline BATS & 27.16417 & 1944.791 & 1016.307 & - & - & 0.1755794 & 0.08579742 \\
\hline TBATS & 55.19522 & 2275.294 & 1275.221 & - & - & 0.2203099 & 0.2208504 \\
\hline Holt's linear Trend & -32.25756 & 2590.665 & 1370.311 & - & - & 0.2367379 & 0.318434 \\
\hline $\operatorname{ARIMA}(5,2,0)$ & 56.14128 & 1571.033 & 803.2858 & 1.020296 & 2.034521 & 0.1387774 & -0.05569346 \\
\hline \multicolumn{8}{|c|}{ Covid 19 Vaccination in Germany } \\
\hline BATS & 1612.141 & 3549.069 & 2606.718 & 0.9580777 & 1.744437 & 0.02667081 & -0.07370485 \\
\hline TBATS & 2009.629 & 4653.615 & 3474.507 & 1.128795 & 2.124129 & 0.03554965 & -0.03150169 \\
\hline Holt's linear Trend & 1770.529 & 6365.875 & 4742.152 & -0.4214333 & 1.962863 & 0.04851964 & 0.6759711 \\
\hline $\operatorname{ARIMA}(1,2,2)$ & 236.9166 & 2325.33 & 1832.852 & -0.01459611 & 0.3729214 & 0.01875295 & -0.04966588 \\
\hline \multicolumn{8}{|c|}{ Covid 19 Infection cases in England } \\
\hline BATS & 107.6703 & 2314.496 & 1099.946 & - & - & 0.1116122 & -0.03304286 \\
\hline TBATS & 20.58434 & 2457.049 & 1257.295 & - & - & 0.1275785 & 0.005440903 \\
\hline Holt's linear Trend & -129.049 & 2501.326 & 1234.822 & - & - & 0.1252982 & 0.07811485 \\
\hline $\operatorname{ARIMA}(3,2,2)$ & 21.07222 & 2335.04 & 1094.787 & 0.5915269 & 1.861959 & 0.1110887 & 0.008794354 \\
\hline \multicolumn{8}{|c|}{ Covid 19 Vaccination in England } \\
\hline BATS & 4522.336 & 24345.38 & 13229.49 & -0.3022656 & 3.709728 & 0.05862319 & -0.05448596 \\
\hline TBATS & 3747.694 & 25234.83 & 14759.43 & -1.587306 & 4.155822 & 0.06540274 & -0.02629988 \\
\hline Holt's linear Trend & -1931.5 & 10180.71 & 8446.923 & -0.5699167 & 0.8149895 & 0.03743044 & 0.6569311 \\
\hline ARIMA(1,2,1) & 762.0841 & 6805.169 & 5108.247 & 0.03485609 & 0.1456201 & 0.02263592 & -0.0004192353 \\
\hline \multicolumn{8}{|c|}{ Covid 19 Infection cases in Israel } \\
\hline BATS & 107.3712 & 867.4313 & 422.0768 & - & - & 0.2267853 & -0.02590818 \\
\hline TBATS & 37.08764 & 1000.514 & 489.6961 & - & - & 0.2631177 & -0.01415636 \\
\hline Holt's linear Trend & -6.588077 & 1088.65 & 465.1592 & - & - & 0.2499339 & 0.0006588116 \\
\hline $\operatorname{ARIMA}(0,2,4)$ & 31.62055 & 876.735 & 422.9822 & 1.017895 & 2.278484 & 0.2272718 & 0.02747328 \\
\hline \multicolumn{8}{|c|}{ Covid 19 Vaccination in Israel } \\
\hline BATS & 1215.568 & 28808.49 & 14687.13 & 25.53409 & 42.14502 & 0.1305031 & 0.01372085 \\
\hline TBATS & 2874.49 & 53288.51 & 28976.59 & 54.98844 & 79.76843 & 0.2574727 & 0.004770556 \\
\hline Holt's linear Trend & -794.6525 & 8768.399 & 6489.681 & 0.03719601 & 3.685765 & 0.05766432 & 0.6406451 \\
\hline $\operatorname{ARIMA}(2,2,2)$ & 151.2771 & 3718.402 & 2822.656 & 0.1809069 & 0.400654 & 0.02508083 & -0.07796272 \\
\hline
\end{tabular}

\section{Conclusion}

This case study was based on COVID19 infection in 5 countries: Russia, the USA, Germany, England, and Israel. The best model for calculating the number of cases of infection is TBATS. Linear vaccination trend model in countries 
TABLE 7. MAPE for infection cases and vaccination on testing data (last 7 days from (4 march 2021) To (10 march 2021) for testing models)

\begin{tabular}{|c|c|c|c|c|c|}
\hline \multicolumn{7}{|c|}{ MAPE for Covid 19 Infection cases } \\
\hline Country & BATS & TBATS & Holt's Linear Trend Model & ARIMA & Best Model \\
\hline Russia & $0.028 \%$ & $0.028 \%$ & $0.026 \%$ & $0.025 \%$ & ARIMA(1,2,4) \\
\hline USA & $0.208 \%$ & $0.188 \%$ & $0.207 \%$ & $0.21 \%$ & TBATS Model \\
\hline Germany & $0.083 \%$ & $0.179 \%$ & $0.149 \%$ & $0.023 \%$ & ARIMA(5,2,0) \\
\hline England & $0.063 \%$ & $0.049 \%$ & $0.026 \%$ & $0.016 \%$ & ARIMA(3,2,2) \\
\hline Israel & $1.206 \%$ & $1.099 \%$ & $1.983 \%$ & $1.331 \%$ & TBATS Model \\
\hline \multicolumn{7}{|c|}{ MAPE for Covid 19 Vaccination } \\
\hline Russia & $7.382 \%$ & $7.363 \%$ & $6.672 \%$ & $4.997 \%$ & ARIMA(2,2,0) \\
\hline USA & $0.311 \%$ & $0.395 \%$ & $0.105 \%$ & $0.274 \%$ & Holt's Linear Trend \\
\hline Germany & $0.76 \%$ & $1.25 \%$ & $1.749 \%$ & $0.202 \%$ & ARIMA(1,2,2) \\
\hline England & $0.388 \%$ & $0.496 \%$ & $0.446 \%$ & $0.196 \%$ & ARIMA(1,2,1) \\
\hline Israel & $0.052 \%$ & $0.802 \%$ & $0.019 \%$ & $0.062 \%$ & Holt's Linear Trend \\
\hline
\end{tabular}

like the USA and Israel, as well as Holt's, is the most accurate. The most applicable model for forecasting vaccination and infection cases in Russia, Germany, and England is ARIMA. Vaccinations and an increase in infection rates are expected to decrease in the short term because Israel and the United States of America will both have significantly increasing vaccination rates, and the governments's recommendations must be followed. Social distancing must also be adhered to because to meet the herd percentage, $60-70 \%$ of the population must be vaccinated.Finally, we want to clarify that COVID 19 may last for a while and therefore we want to hint in this study that we are not deceived by the decrease in infection cases also work to increase the number of vaccinations to reach the herd percentage. We also want to point out that these models are the best forecast models during the period from January 3, 2020, to March 3, 2021.As there are some geographical and demographic variables that affect the accuracy of these models. According to our experiments, the parameters of these models must be updated weekly to obtain accurate results with the least possible errors.

\section{Data Availability Statements}

The data that support the findings of this study are openly available in for vaccine data https://ourworldindata.org/grapher/daily-covid-19-vaccination-doses, and for infection https:// covid19. who. int/info/.

(1) BATS, TBATS, Holt's Linear Trend, and ARIMA Models BATS, TBATS , Holt's Linear Trend, ARIMAModels were fitted by using R software.

(2) Data set From (3 January 2020) To (10 march 2021) cumulative daily data set of covid 19 infection cases and using the period from (3 January 2020) To (3 march 2021) for training data and using last 7 days from (4 march 2021) To (10 march 2021) for testing models and for vaccination data till 10 march 2021 and last 7 days from (4 march 2021) To (10 march 2021) for testing models

\section{ACKNOWLEDGEMENT}

The work was supported by Act 211 of the Russian government, contract No. 02.A03.21.0011. The work was supported by the Russian Ministry of Science and Higher Education (government order FENU-2020-0022).

I'm Mostafa Abotaleb. I would like to thank Dr: Natalia Shaburova. Head of Department of Postgraduate Studies of the Federal State Autonomous Educational Institution of Higher Education South Ural State University (national research university) (NRU) for her valuable guidance throughout my studies. You provided me with the tools that I needed to choose the right direction and successfully complete my dissertation. I will never forget what I learned. I will remember it forever as I promised you.

\section{CONFLICTS OF INTEREST}

The authors declare that there are no conflicts of interest regarding the publication of this article. 


\section{Authors Contribution Statement}

Motivation / Concept: Mostafa Abotaleb, Tatiana Makarovskikh, Harun Yonar and Pradeep Mishra Design: Pradeep Mishra

Control/Supervision: Mostafa Abotaleb Harun Yonar and Amr Badr.

Data Collection and / or Processing: Aynur Yonar, Kadir Karakaya, Amr Badr.

Analysis and / or Interpretation: Mostafa Abotaleb, Tatiana Makarovskikh, and Harun Yonar.

Literature Review: Aynur Yonar, Kadir Karakaya and Amr Badr.

Writing the Article: Mostafa Abotaleb, Tatiana Makarovskikh and Pradeep Mishra.

\section{REFERENCES}

[1] Abotaleb, M.S.A., Predicting COVID-19 cases using some statistical models: An application to the cases reported in China Italy and USA, Academic Journal of Applied Mathematical Sciences, 6(4)(2020), 32-40. doi . org/10. 32861/ajams . 64 . 32 . 40.

[2] Abotaleb, M.S.A., Makarovskikh, T., The Research of Mathematical Models for Forecasting Covid-19 Cases, In: Strekalovsky A., Kochetov Y., Gruzdeva T., Orlov A. (eds) Mathematical Optimization Theory and Operations Research: Recent Trends. MOTOR 2021. Communications in Computer and Information Science, vol 1476. Springer, Cham., 2021. https://doi .org/10.1007/978-3-030-86433-0_21.

[3] Abotaleb, M.S.A., Makarovskikh, T.A., Development of algorithms for choosing the best time series models and neural networks to predict COVID-19 cases, Bulletin of the South Ural State University. Ser. Computer Technologies, Automatic Control, Radio Electronics, 21(3)(2021), 26--35. DOI : $10.14529 /$ ctcr210303.

[4] Abotalebi, M., Makarovskikh, T., System for forecasting COVID-19 cases using time-series and neural networks models, Engineering Proceedings, 5(1)(46)(2021). https://doi .org/10.3390/engproc2021005046.

[5] Bubar, K.M., Reinholt, K., Kissler, S.M., Lipsitch, M., Cobey, S. et al., Model-informed COVID-19 vaccine prioritization strategies by age and serostatus, Science, 371(6532)(2021), 916-921.

[6] Chatfield, C.A., The Analysis of Time Series: An Introduction, R. CRC Press, 2019.

[7] De Livera, A.M., Hyndman, R.J., Snyder, R.D., Forecasting time series with complex seasonal patterns using exponential smoothing, Journal of the American Statistical Association, 106(496)(2011), 1513-1527.

[8] Frain, J., Lecture Notes on Univariate Time Series Analysis and Box Jenkins Forecasting, Economic. Research and Publications, 1992.

[9] Holt, C.E., Forecasting Seasonals and Trends by Exponentially Weighted Averages (ONR Memorandum No. 52), Carnegie Institute of Technology, Pittsburgh USA, 1957.

[10] Sardar, I., Karakaya, K., Makarovskikh, T., Abotaleb, M., Hussain, S.A. etal., Machine learning-based Covid-19 forecasting: Impact on Pakistan stock exchange, International Journal of Agricultural and Statistical Sciences, (2021). DocID:https://connectjournals.com/ Q3899.2021.17.53.

[11] Kirchgässner, G.J., Introduction to Modern Time Series Analysis, Springer Science \& Business Media, 2012.

[12] Makarovskikh, T.A., Abotaleb, M.S.A., Automatic selection of ARIMA model parameters to forecast COVID-19 infection and death cases, Bulletin of the South Ural State University. Series: Computational Mathematics and Software Engineering,10(2)(2021), 20--37.(in Russian) DOI : $10.14529 / \mathrm{cmse} 210202$.

[13] Makarovskikh, T., Abotaleb, M., Comparison Between Two Systems for Forecasting Covid-19 Infected Cases. In: Byrski A., Czachórski T., Gelenbe E., Grochla K., Murayama Y. (eds). Computer Science Protecting Human Society Against Epidemics. ANTICOVID 2021. IFIP Advances in Information and Communication Technology, vol 616. Springer, Cham., 2021. https://doi.org/10.1007/ 978-3-030-86582-5_10.

[14] Mishra, P., Fatih, C., Rawat, D., Sahu, S., Pandey, S.S.et al., Trajectory of COVID-19 data in India: Investigation and project using artificial neural network, Fuzzy Time Series and ARIMA Models, Annual Research \& Review in Biology, 35(9)(2020), 46-54.

[15] Mishra, P., Al Khatib, M.G., Sardar, I. et al., Modeling and forecasting of sugarcane production in India, Sugar Tech., 23(2021), $1317-1324$. https://doi.org/10.1007/s12355-021-01004-3.

[16] Mishra, P., Matuka, A., Abotaleb, M.S.A., Weerasinghe, W.P.M.C.N., Karakaya, K. et al., Modeling and forecasting of milk production in the SAARC countries and China, Modeling Earth Systems and Environment, (2021), 1-13.

[17] Mohammed, J., Khatib, A.M., Mishra, P., Adjei, P., Singh, P.K. et al., Modeling and forecasting of Covid-19 from the context of Ghana, African Review of Economics and Finance, (2020), 1-18.

[18] Rostami-Tabar, B., Rendon-Sanchez, J.F., Forecasting COVID-19 daily cases using phone call data, Applied Soft Computing, 100(2021), 106932.

[19] Seale, H., Heywood, A.E., Leask, J., Sheel, M., Durrheim, D. N. et al., Examining Australian public perceptions and behaviors towards a future COVID-19 vaccine, BMC Infectious Diseases, 21(1)(2021), 1-9.

[20] Tekindal, M.A., Yonar, H., Yonar, A., Tekindal, M., Çevrimli, M.B. et al., Analyzing COVID-19 outbreak for Turkey and eight country with curve estimation models, Box-Jenkins (ARIMA), Brown linear exponential smoothing method, autoregressive distributed lag (ARDL) and SEIR Models, Eurasian J Vet Sci, Covid-19 Special Issue, 142-155.

[21] Yonar, H., Yonar, A., Tekindal, M. A., Tekindal, M., Modeling and forecasting for the number of cases of the COVID-19 pandemic with the curve estimation models, the Box-Jenkins and exponential smoothing methods, EJMO, 4(2)(2020), 160-165.

[22] Young, W.L., The Box-Jenkins approach to time series analysis and forecasting: principles and applications, RAIRO-Operations ResearchRecherche Opérationnelle, 11(1977), 129-143. 
APPENDIX
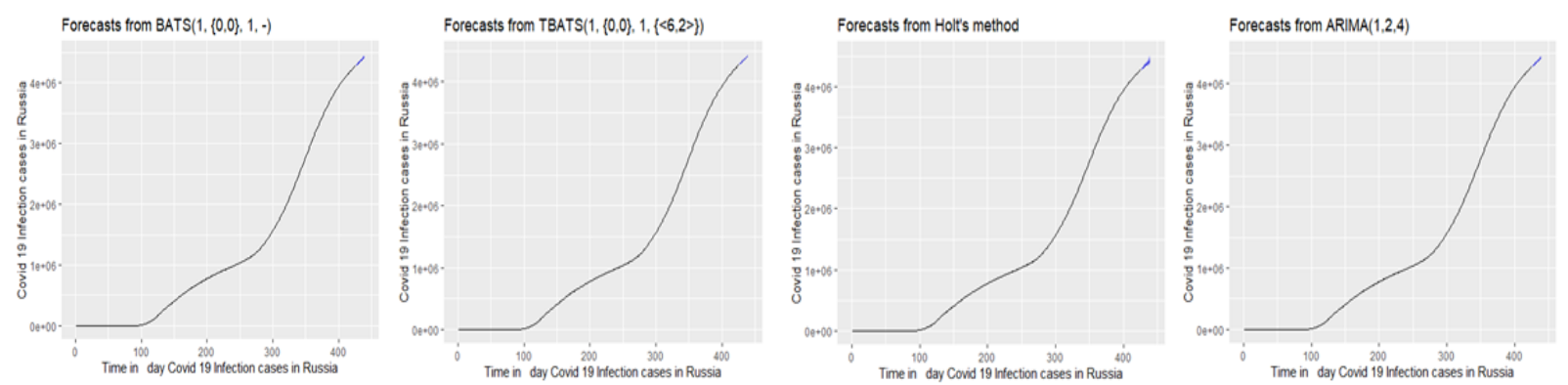

FIGURE 3. Forecasting of infection case using different models in Russia
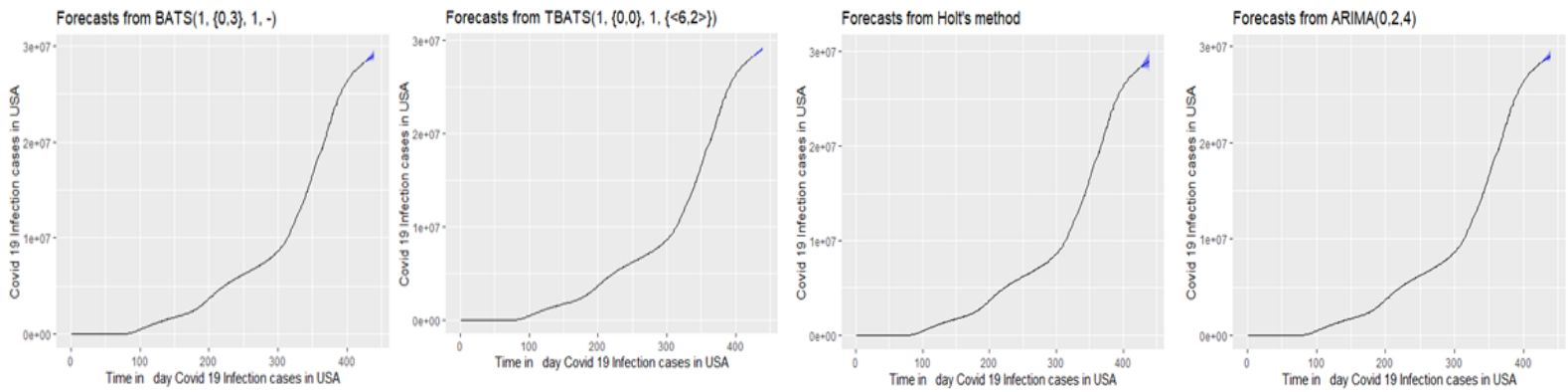

FIGURE 4. Forecasting of infection case using different models in USA
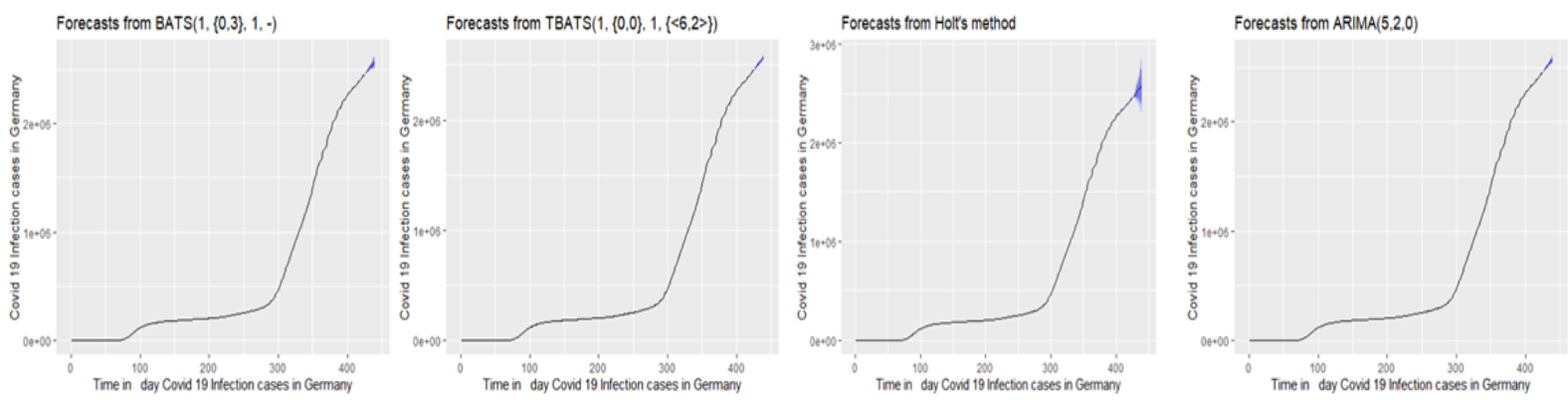

FIGURE 5. Forecasting of infection case using different models in Germany 

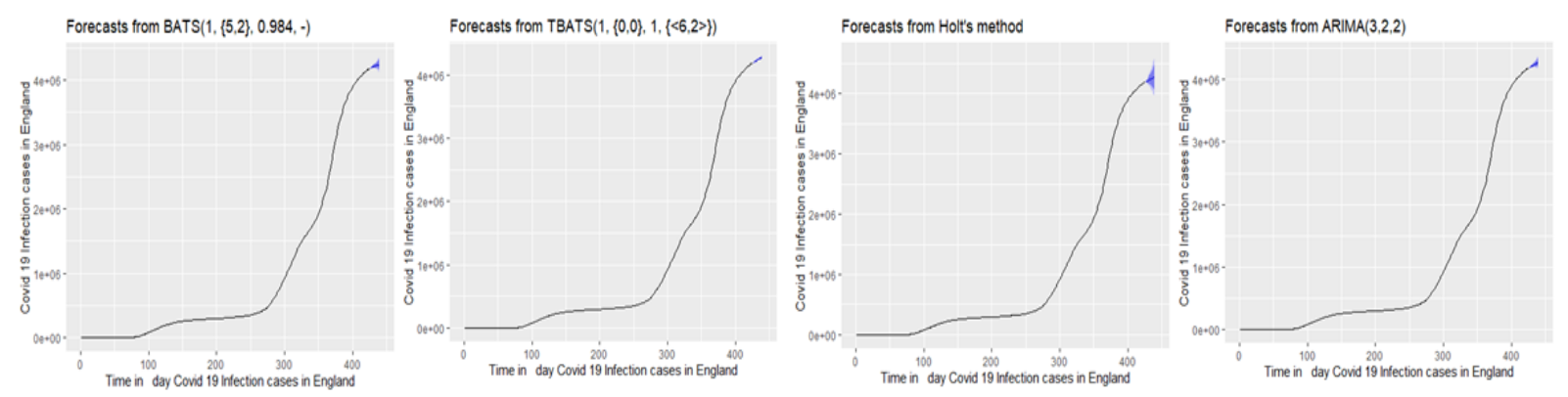

FIGURE 6. Forecasting of infection case using different models in England
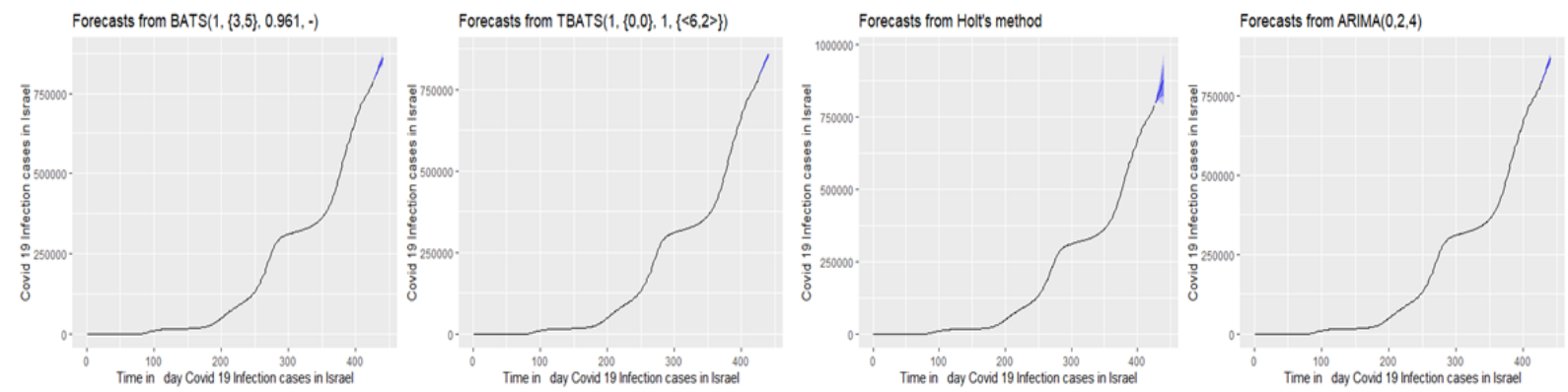

FIGURE 7. Forecasting of infection case using different models in Israel
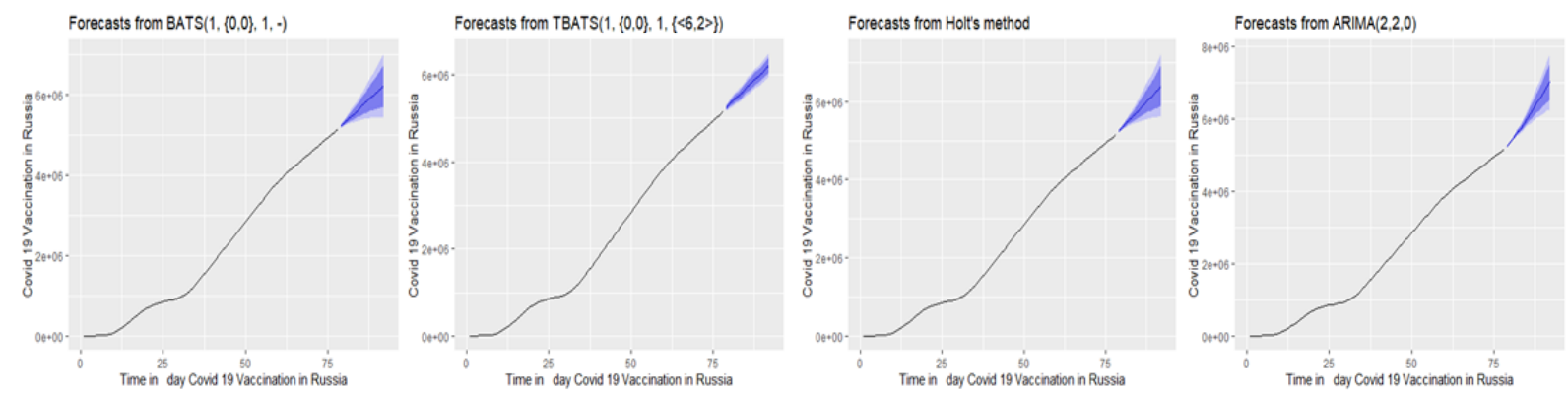

FIGURE 8. Forecasting of Covid 19 Vaccination using different models in Russia
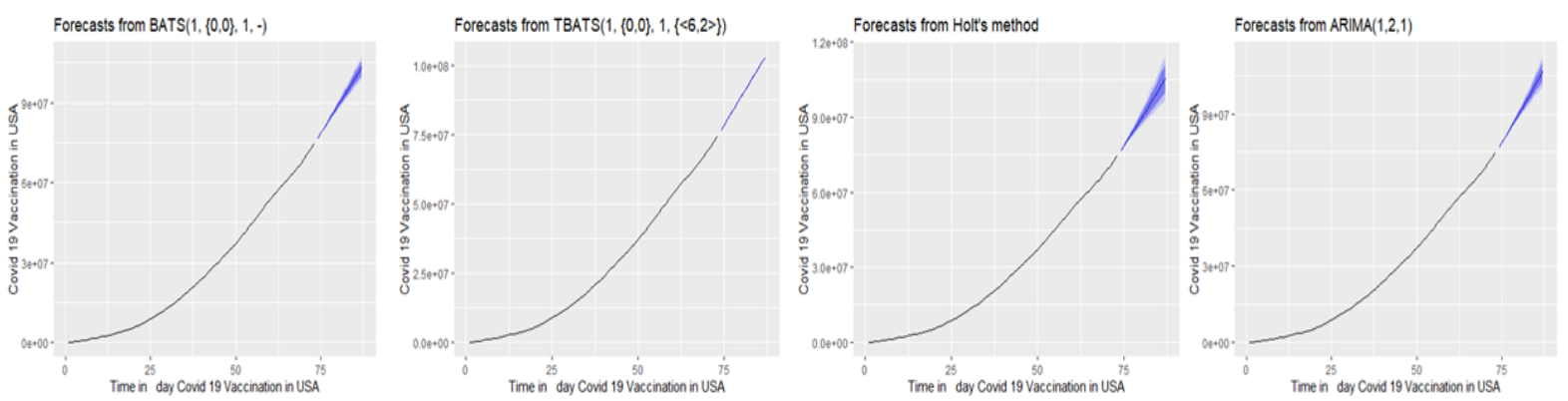

FIGURE 9. Forecasting of Covid 19 Vaccination using different models in USA 

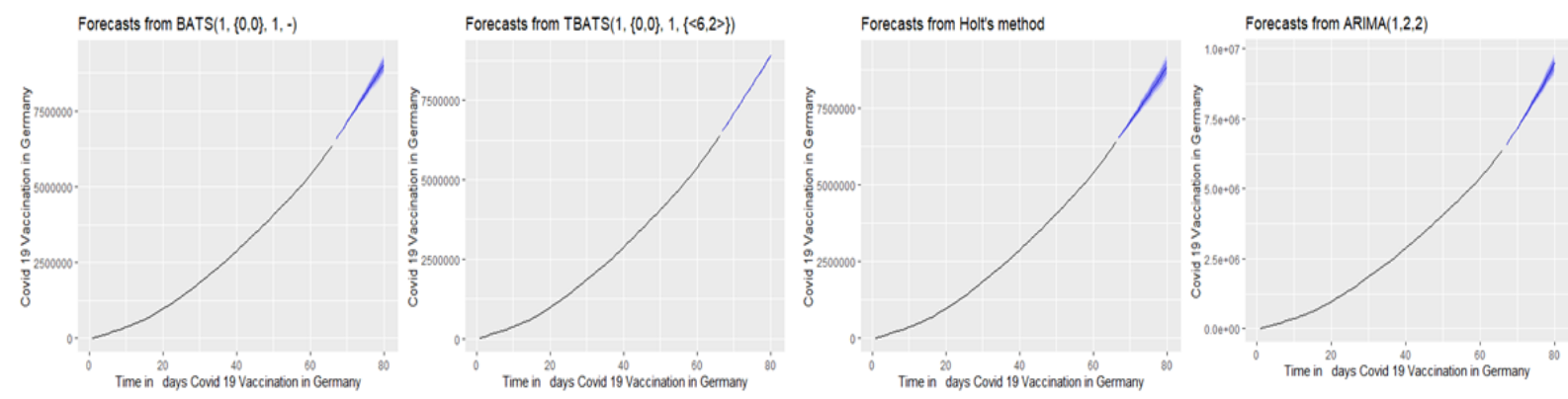

FIGURE 10. Forecasting of Covid 19 Vaccination using different models in Germany
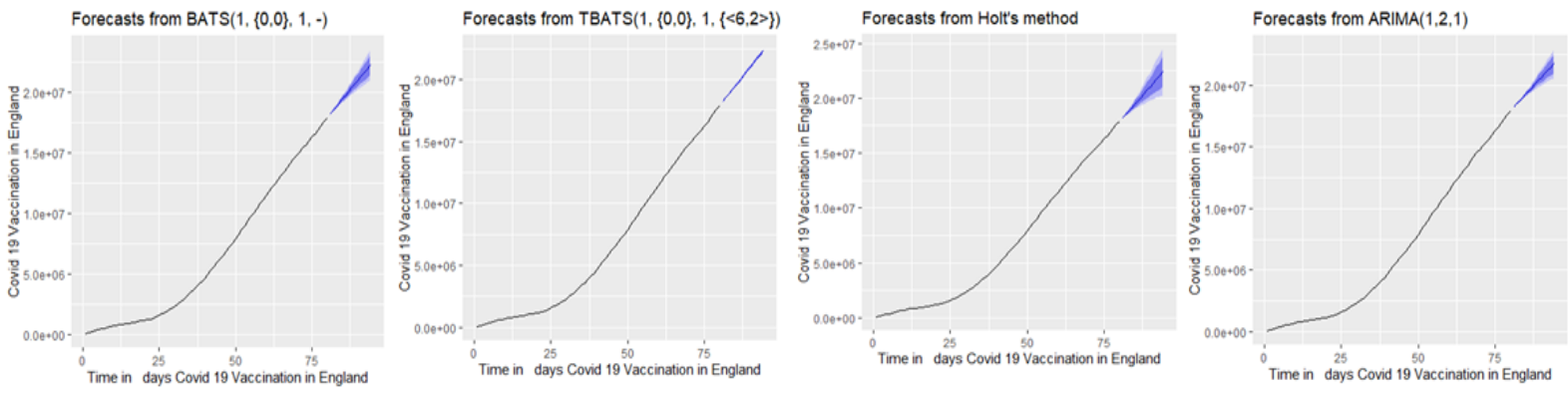

Figure 11. Forecasting of Covid 19 Vaccination using different models in England
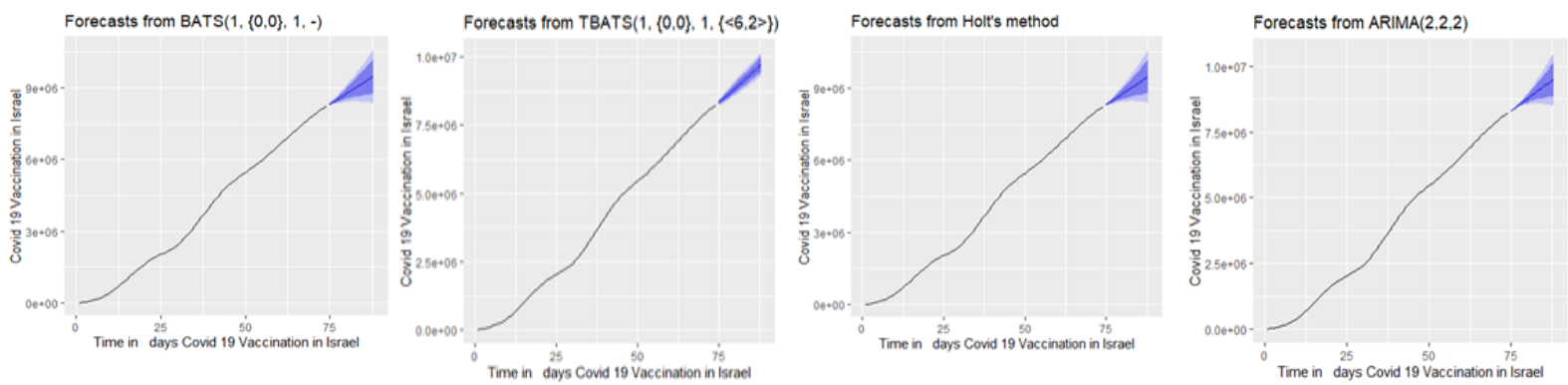

FIGURE 12. Forecasting of Covid 19 Vaccination using different models in Israel 